\title{
An Examination Of The Roles Of State School Psychology Consultants
}

\author{
Chung-Hau Fan, Idaho State University, USA \\ Jennifer L. Gallup, Idaho State University, USA \\ I-Chen $\mathrm{Wu}$, University of British Columbia, Canada \\ Jeremy W. Ford, Boise State University, USA
}

\begin{abstract}
With the increasing visibility of state school psychology consultants (SSPCs) across the nation, there is a pressing need to understand their roles and functions relative to serving their stakeholders. In addition, it is unclear whether current SSPC job responsibilities are aligned with the National Association of School Psychologists' (NASP) practice model, which can help ensure the quality of school psychological service delivery. A qualitative case study design was conducted with interviews to examine the job responsibilities of SSPCs (e.g., provision of consultation, policy guidance, professional development, coordination of professional resources and services). The qualitative analysis revealed three main themes: (a) service provision, (b) collaborative roles and efforts, and (c) systems improvement across the state, which were aligned with different levels of domains in the NASP practice model. The findings can help inform the roles and responsibilities of SSPCs and the development of new SSPC functions. Implications for conceptualization of the SSPC initiative in relation to the NASP practice model for future practice are discussed.
\end{abstract}

Keywords: State School Psychology Consultants; NASP Practice Model; System Reform

\section{INTRODUCTION}

1 n March 2010, NASP revised and approved a formal model for comprehensive and integrated school psychological services (also known as the NASP practice model). It delineates ten practice domains of school psychologists as well as a general framework within which their services should be provided (NASP, 2010). According to NASP (2010), this broad-based service delivery model can best serve the needs of all students while also supporting teachers' ability to teach; thus, the adoption of this practice model across school districts as well as at the state level can help ensure the school psychologists' maximum effectiveness, efficiency, and quality of service provision. Specifically, NASP lists a variety of potential benefits of adopting the practice model on its website (NASP, n.d.), including (a) Improved Academic Engagement and Achievement, (b) Facilitation of Effective Instruction, (c) Support for Positive Behavior and Socially Successful Students, (d) Support for Diverse Learners, (e) Creation of Safe, Positive School Climates, (f) Strengthening of Family-School Partnerships, (g) Improved Assessment and Accountability, and (h) Wiser Investments of Existing Resources. In all, these expected positive outcomes at the individual student as well as the system levels appear to be commensurate with the coherently defined practice domains. Additionally, the comprehensive NASP practice model echoes the continuous call for the expansion of school psychologists' roles and functions by utilizing a variety of expertise and skills (e.g., assessment, consultation, mental health services, home-school collaboration) to promote positive learning outcomes for all students (Reschly, 2008; Ysseldyke, Reynolds, \& Weinberg, 1984). Further, the implementation of this comprehensive practice model may help facilitate effective translation of federal law requirements such as the Every Student Succeeds Act (ESSA, 2015) into state policy reform as well as the use of evidence-based practices (EBPs) in local school districts such as implementation of multi-tiered system of support (MTSS) for academic and behavioral interventions and universal screening to identify at-risk students (Eklund, Rossen, Charvat, Meyer, \& Tanner, 2016).

\section{The Emergence of State School Psychology Consultants}

Most recently, some state education agencies (SEAs) started recruiting school psychology practitioners into their statelevel team collaboration and system-wide programming efforts in to increase student learning and achievement. For 
instance, the website of the Florida Department of Education (DOE) introduces its state school psychology consultant (SSPC) acting as a liaison between the DOE and practicing school psychologists on school psychology-related issues by providing technical assistance in matters related to federal and state laws and regulations as well as state policies and initiatives affecting the practice of school psychology (Florida DOE, n.d.). Another SSPC description can be found on the Wisconsin Department of Public Instruction (DPI) website (Wisconsin DPI, n.d.):

The school psychology program consultant at the Wisconsin Department of Public Instruction (DPI) supports school psychologists, school districts, universities, state agencies, professional organizations, and parents....The school psychology consultant is a liaison to the Wisconsin School Psychologists Association, the seven Wisconsin universities with training programs in school psychology, the Wisconsin Council on Mental Health, as well as the Council's Children and Youth Committee, offers technical assistance on school psychology issues, and provides statewide training consistent with the DPI philosophy that the delivery of services is offered as a collaboration.

The NASP also has an informal description (i.e., not available in any published document) about this consultant position:

The State Consultant(s) are the person(s) within your SEA who works in a capacity where they represent, communicate with, and/or supervise school psychologists. They may provide leadership, consultation, and technical assistance to develop and implement the program of school psychological services in each local school system. They may be assigned to a variety of initiatives such as school mental health, special education and alternative services, and the policies, regulations, research, and data collection related to these initiatives, and/or serve as a liaison between school psychologists/supervisors of school psychologists and the SEA on mental health and learning issues affecting children.

According to the NASP, each state's consultant, if any, was identified by its state's NASP delegate and leadership (e.g., president) of the professional association of school psychologists. The NASP uses the identified SSPCs as an avenue to communicate issues that may affect school psychological services at the state level. During each year's annual convention, NASP leaders host a State School Psychology Consultant Network meeting to discuss issues of professional policy and practice impacting school psychologists that require input, involvement, or information from different states (e.g., the review and revision of NASP standards). It is important to note that state consultants are part of the SEA teams rather than the NASP, so their roles and functions can vary from state to state.

In summary, an SSPC is expected to provide leadership, technical assistance, policy guidance, and initiatives that directly pertain to school psychological services. With the elevation of school psychological services to the state level of practice, school psychologists can function in influential positions to effectively integrate resources and policies to meet the legal and ethical expectations (e.g., identifying and serving students with special needs, equity of resources allocation) emphasized in federal regulations (e.g., ESSA, 2015) and the NASP practice guidelines. Given that SSPCs can fulfill critical leadership roles in state policy change and guidance, it is reasonable to believe that promotion of such positions and improvement of their functions may benefit direct or indirect stakeholders throughout a state (e.g., practicing school psychologists, special education teachers, university school psychology trainees).

To date, no studies have examined initiatives to recruit school psychologists at the state level to serve their stakeholders with school psychology and related services. Also, the NASP practice domain, Legal, Ethical, and Professional Practice, recommends school psychologists to provide services consistent with professional standards (e.g., NASP standards), collaborate with other professionals, and apply professional work characteristics needed for effective practice. It is unclear whether job responsibilities and leadership roles of current SSPC positions in different states are well aligned with the NASP practice model in the scope of their service provision, assuming multiple benefits of adopting the NASP practice model (NASP, n.d.). Without a close examination, it is difficult to determine whether current SSPCs can help schools and families achieve desirable outcomes as described by the NASP practice model (e.g., improving academic achievement, enhancing positive behavioral and social behaviors, supporting diverse learners, and creating positive and safe learning environments). Thus, this preliminary study was aimed to answer two research questions:

1. What are the perceived roles and functions of SSPCs?

2. How are the perceived roles and functions of SSPCs aligned with the NASP practice model? 
The potential goals of the current study were three fold: (a) for those SEAs that do not have an SSPC position to consider creating one to serve their states, (b) for those SEAs that already have their own SSPC positions to consider making changes to the current roles and functions, and (c) for those school psychologists who may be interested in applying for such positions to obtain pertinent information.

\section{METHOD}

\section{Research Design}

A case study design was selected because the intent was to understand how the culture works specifically within the issue of defining the roles of an SSPC and the perceptions of the SSPC role related to the NASP practice model. The research involved the study of selected cases within specific organizations (Yin, 2014). Case study is defined as the qualitative approach in which the investigators explore the bound system or case through detailed in-depth data collection. An ethnographer focuses on examining shared patterns and beliefs related to a unit of analysis typically in larger groups of individuals while a case study grounded within an ethnographic study allows researchers to pare down the study to a selected group of individuals and focus on a particular topic of interest (Creswell, 2013).

\section{Participants}

A research proposal was approved by the NASP Research Committee and an SSPC directory was provided for the current study use. The directory included 29 states' contacts (i.e., name, employed institution/agency, work phone number, email). Considering clarity and the intended usage of the research findings (e.g., informing future SSPC job creation, modification, and/or application), the current study was aimed to focus on those full-time SSPC positions directly associated with the SEAs. Purposeful sampling was utilized to show different perspectives on the selected group of SSPCs when developing themes across states. Those SSPCs who only acted as advisors for SEAs but primarily worked for state universities or local school districts were excluded from our participant invitation to avoid data dilution (Creswell, 2013). As a result, the available 29 SSPC contacts from the directory were narrowed down to 12 potential participants who held full-time SSPC jobs in their SEAs. Then, an invitation email was sent out and six SSPCs responded. One respondent indicated that she did not qualify for the recruiting criteria of the current study and was thanked for her time and notification. The other five SSPCs participated in phone interviews with the first author.

The characteristics of the interviewed participants are summarized in Table 1. All five participants were females. Four were White and one self-identified as Latina. The majority held terminal degrees as educational specialists in school psychology and had been practicing as SSPCs for a minimum of 2 years. All participants identified themselves as the only SSPCs serving their states.

Table 1. Demographics of the Participants

\begin{tabular}{l|l|l|l|l|l}
\hline & Participant 1 & Participant 2 & Participant 3 & \multicolumn{1}{|c}{ Participant 4 } & \multicolumn{1}{c}{ Participant 5 } \\
\hline Gender & Female & Female & Female & Female & Female \\
\hline Ethnicity & White & White & White & Latina & White \\
\hline Region & South Atlantic & East South & Mountain & South Atlantic & North Central \\
\hline Education & MA, CAGS & Ed.S. & Ed.S. & Ed.S. & Ed.S. \\
\hline Years of Experience & 2 & 2 & 3 & 2 & 6 \\
\hline
\end{tabular}

Note: CAGS = Certificate of Advanced Graduate Studies; Ed.S. = Educational Specialist degree

\section{PROCEDURE}

A qualitative case study design was used for data exploration because no previous studies have been reported directly related to the current research questions. A semi-structured interview process was conducted for the participants to share their own experiences and thoughts in details regarding their role as SSPCs in their states. To address the first research question, each participant was asked an open-ended question, "What are your job responsibilities as a state school psychology consultant?" Some follow-up questions were used for elaboration and clarification of the interviewees' responses. Each interview lasted from 30 to 45 minutes and was transcribed verbatim. The current study 
analyzed part of the semi-structured interview data to efficiently inform the research question being investigated. Interested readers can consult the corresponding author for the whole set of the semi-structured interview questions.

Throughout the processes of data analysis, the researcher conducted member checking and an audit trail in order to ensure that no misinterpretation of the participants' views or comments had taken place. The transcripts, along with the researcher's comments, were sent via email to the participants for correcting any inaccuracies (Creswell, 2013; Hays \& Singh, 2011). The participating SSPCs were given time to read the transcriptions and provide any additional feedback or reflections based on the comments of the researcher. They were also given the opportunity to correct any of the transcriptions to reflect what they intended to say in the event that a word or phrase was missed in the transcription process. All five participants reviewed the transcripts and comments and verified any changes with the researcher.

\section{DATA ANALYSES}

Data analysis began after the first data set was collected by the first author through the interview of the first participating SSPC. Analysis of the interviews followed the modified Van Kaam method (Moustakas, 1994). The analysis consisted of bracketed assumptions that identified non-repetitive and non-overlapping statements with their interview transcripts. Transcripts reflected textural and structural descriptions of the experiences (Creswell, 2013; Hays \& Singh, 2011). Reduction and analysis of specific statements were used to tease out overarching themes (Simon \& Goes, 2012). At the end of analyzing the interview transcripts of the five SSPCs, the data reached the level of saturation (i.e., with no more non-overlapping statements) for using a case study design (Creswell, 2013).

\section{Validation of Invariant Constituents and Themes}

Final identification of themes was validated against the interview text of each participant to ensure that they were comparable with the experiences of the participants and validated with a second researcher. A second researcher read the first author's field notes and asked questions to help the researcher examine assumptions and consider alternative ways of looking at the data through a process called peer debriefing (Bloomberg \& Volpe, 2012). To further validate the findings, all interviews were coded and verified to establish inter-rater reliability for "checking on the consistency between raters which reduces the potential bias of a single researcher collecting and analyzing data" (Bloomberg \& Volpe, 2012, p. 113). Each invariant constituent was explicitly expressed within the text or found attuned with the social experiences described by the participants. The sets of interview data were coded by the first researcher and then verified by the other two researchers (i.e., multiple coding). Any inconsistencies between codes were discussed and agreed upon in the final process of validating the codes against the research questions. Initially, substantial agreement was met at about $80 \%$. After discussion, the researchers reached $100 \%$ agreement for each identified code and category to ensure that the research questions were being addressed by thoroughly unpacking the data (Creswell, 2013).

\section{Clustering and Thematizing}

Clusters were formed from the similarities between descriptive labels for each invariant constituent as they related to the research questions. The identified labels were combined to form final themes in the research. Emergent codes were used to help identify and confirm themes. Table 2 describes the relationships between the clusters of thematic codes (i.e., core ideas) and the development of the final themes.

\section{RESULTS}

\section{Roles and Functions of SSPCs}

The SSPCs who participated in the current study demonstrated a wide range of experiences, knowledge, and expertise in promoting school psychological services in their states. To address the first research question, the analysis of the interviews revealed three main themes: (a) service provision, (b) collaborative roles and efforts, and (c) system improvement across the state. There were also core ideas identified under each main theme, which described the job responsibilities of the SSPC position. 


\section{Theme 1: Service Provision}

When examining the reported job descriptions of the participating SSPCs, the first theme extracted from the interviews was service provision. This theme was correlated with the other two themes (i.e., double-coding across themes). All five participants clearly described the contents of their services from which four core ideas emerged: consultation services, professional development, resource arrangement and development, and data-based decision making.

First, the SSPCs reportedly functioned as consultants to help assist school districts in understanding the application of state regulations and procedures. For example, one participant stated,

"I'm a contact for school psychologists and/or special education directors when they have questions related to our state regulations or the process or the best practices or, you know, if they're not sure where to go or who to ask, I'm a person that people can call and ask if it has to do with evaluation or special education or anything that's school psychology related."

Other points mentioned were related to data interpretation for special education eligibility purposes or how to work with challenging cases such as students with severe emotional disabilities. One participant noted that she could provide guidance or suggestions for school-based teams to consider; however, she had to be careful in a consultative relationship so as not to inadvertently make decisions for the team because the state consultant should not be considered as a member serving on a multidisciplinary team.

Second, the SSPCs helped disseminate the most current practices and prepare practitioners for further systemic changes through multiple training opportunities. One participant mentioned,

"We have school psychologists that have been in this field for a really long time and aren't necessarily up to date with the new practice model. We have psychologists that are coming from non-approved programs or from out of state, and they just need to be trained on state special education eligibility criteria and expectations."

In addition, training might also require collaboration with professional organizations. One participant indicated that she assisted her state association of school psychologists by hosting face-to-face in-service training for a variety of topics such as positive behavioral interventions and supports (PBIS). This participant also expressed that training and technical assistance provided could be aligned with state policy changes such as transitioning from a traditional refertest-place model to an RtI framework when considering SLD eligibility.

Third, all of the participating SSPCs described their involvement in resource development and had management plans to allocate available internal and external resources. They made systemic decisions to provide various kinds of services based on the state-wide data collection and interpretation. One frequently mentioned point was the use of internal resources (e.g., from SEAs) as managing and organizing resources on the websites, which served as a communication channel (e.g., posting state guidance documents) for different mental health service providers, such as school psychologists, school social workers, and school counselors. Another type of resource management was related to state funds for different highly prioritized projects with collaboration with local districts (e.g., expansion of PBIS, initiatives for youth development academies). In addition to managing state websites and funds, one participant pointed out the importance of recruiting and organizing external resources. She stated,

"I think it's an important position [SSPC] for connecting with the institutes of higher education, getting resources to districts that might not have as many resources, having leadership, coordinating with other state agencies around school mental health." 
Fourth, the results indicated the SSPCs' frequent engagement in data-driven decision-making processes as a means of maintaining professional standards for practice. An example expressed by one participant was,

"I pull data mostly around our special education identification rates across the state, and I actually help when districts need information about under-or over-identification compared to our state and national trend data for specific disability areas. I try to help problem solve around some of that. I look at that data a lot, and I work with school psychologists in the districts to help them to understand how to look at and analyze their own district level data."

\section{Theme 2: Collaborative Roles and Efforts}

Five core ideas were discovered in the next overarching theme of collaborative roles and efforts within the role of the SSPC. It appeared that an SSPC's role was highly collaborative in nature and multifaceted with collaborations between school district leaders and educators, university partners, local stakeholders, mental health professionals, as well as administrators at different levels of service delivery.

All of the five participants described their collaboration with colleagues within different departments or divisions in the SEAs. The representation of a school psychologist's voice in different service committees at the state level was highly valued and appreciated by the participants. This was specifically noted by one participant:

"I'm the only school psychologist on staff. If anybody is working on any project needing a school psychology perspective, then I sit on, like those work committees or work plans.... I'm the school psychology voice within state department work."

Second, all the participants indicated their involvement in collaborative work with people in local school districts. Based upon their experiences and observations, those LEAs had needs for support above and beyond just the consultation regarding special education eligibility policies and procedures. For illustration, one participant stated,

"If their self-assessment reports come back and they [LEAs] have things in place that aren't adequately addressing pre-referral practices, interventions, or evaluation procedures such as being sensitive to certain cultural factors that may be contributing to some issues of disproportionality, then those are areas where I can go in and help provide some targeted technical assistance in those areas."

Third, three out of five participants collaborated frequently with professional associations and/or other agencies for service delivery or professional training purposes. One participant indicated her continuous efforts of state-wide collaboration with agencies to create more of a comprehensive behavioral health system beyond school. For instance, her state had a commission for suicide prevention and an office of suicide prevention. Therefore, she collaborated with the agencies to get the statewide data on suicide for planning prevention and intervention after prioritizing the needs across the state. Another example was about arranging professional development opportunities. One SSPC stated,

"Training that has been professional development like the NASP prepared training, so we had two or three years of that where I partnered to help do that training for our state organization."

Fourth, four out of five participants reported collaborating with their state universities. Such collaboration with school psychology training programs served as a conduit to help develop seminars, conferences, professional development, and understanding of the laws and standards related to the SSPC position. Through collaborative efforts, a participating SSPC was dedicated to enhancing competencies of school psychologist candidates in higher education. She had one research assistant and two school psychologist interns from a partner university, who worked with her one day per week to learn from a systemic perspective of school psychology and special education related issues. In this case, having a partnership between SSPC and higher education seemed to be mutually beneficial by sharing resources for training, research, and clinical practice. 
Finally, a critical element identified within the construct of collaboration was leadership. Four out of five interviewed SSPCs served on different leadership teams to lead or guide professionals to facilitate their service provision (e.g., professional development systems [PDS] management team, advisory committee of funds application, leadership team for RtI/MTSS implementation, other state system improvement teams).

\section{Theme 3: System Improvement Across the State}

The third theme was system improvement across the state. All five participants indicated their plans and efforts focused on the various changes in state regulations and policies as they pertained to special education and system improvements (e.g., school climate transformation, suicide prevention, improving high school graduation rates for African Americans and Native Americans with disabilities). The three core ideas identified were policy change, RtI/MTSS, and program evaluation, which were closely correlated. The most prominent idea was program evaluation, which was dedicated to SSPCs' involvement in different types of evaluation (e.g., effectiveness of in-service training, job performance of school psychologists, efficiency of using grant resources). For example, one SSPC stated,

"I do hire an evaluation person.... When I do trainings for school psychology, I'll like to know how that's going, um, you know, what people have gotten out of the training, what they're learning, and do they find it beneficial?"

As to the ideas regarding policy change and RtI/MTSS, one participant stated, "Myself and our SLD consultant have been the two primary people involved in facilitating the work that led to the changes in our policy that were put forth to our State Board of Education on evaluating and identifying learning disabilities." Such change was reportedly aligned with the adoption of RtI to provide assistance to promote all students' academic, behavioral, and socialemotional success. In addition, the value of SSPCs' leadership in systemic reforms as well as school psychologists' active involvement were clearly expected by the stakeholders. As a result, changes in policies and reorganization of service delivery systems have turned into a call for redefining school psychologists' job description. One participant stated, "We're in the process of redefining roles and responsibilities at the state level, so it's in our rules and regulations regarding what we expect out of our school psychologists. We're aligning that to the [NASP] practice model." This effort was elaborated by another SSPC regarding the change in her state: "I've been working on resources for our state model evaluation system for evaluation rubrics for school psychologists, and then guidance documents for doing school psychologist evaluations." Taken together, it appeared that there was an emerging trend of refining the job responsibilities of school psychologists to address the recent special education policy change toward using instructionbased approaches (i.e., RtI/MTSS) for SLD diagnosis. One participant further expressed, "My hope is that we will see higher retention rates of school psychologists because of that job satisfaction" with the expansion of school psychologists' roles and functions in the revision work of her state's regulations.

\section{Alignments with the NASP Practice Domains}

The second research question was to examine the relations between the perceived SSPCs' roles and the NASP practice domains. The results are summarized and presented in Table 2. The identified core ideas in Theme 1 suggested that the participating SSPCs were engaged in systematic data collection from multiple sources (e.g., school districts, professional agencies) to facilitate effective data-driven decision making in a variety of problem-solving processes (e.g., prioritizing and addressing needs across the state, service delivery for prevention and intervention). Such practices were aligned with the first NASP practice domain: Data-Based Decision Making and Accountability. In addition, the consultation services through different means of communication (e.g., websites, phone calls) that SSPCs offered to diverse populations of consultees and stakeholder groups were deemed to promote effective implementation of services. This addressed the principles in the second NASP practice domain: Consultation and Collaboration. Furthermore, SSPCs as the leading school psychologists at the state level of practice to arrange professional development opportunities and incorporate EBPs for improvement activities that promoted learning and mental health services across the states. Such statewide service delivery efforts definitely lifted the expectation in the fifth NASP practice domain: School-Wide Practices to Promote Learning to a higher (state) level. 
Table 2. Themes and Associated Core Ideas and Related NASP Practice Domains

\begin{tabular}{l|l|c}
\hline \multicolumn{1}{c|}{ Theme } & \multicolumn{1}{c}{ Associated core ideas } & \multicolumn{1}{c}{ NASP domains } \\
\hline \multirow{2}{*}{ Service provision } & $\begin{array}{l}\text { Consultation services (e.g., helping district understand the } \\
\text { Professional development (e.g., ethics or RtI training) } \\
\text { Resource arrangement and development (e.g., website } \\
\text { development and management) } \\
\text { Data-based decision making }\end{array}$ & $1,2, \& 5$ \\
\hline \multirow{2}{*}{ Collaborative roles and efforts } & $\begin{array}{l}\text { Collaboration in the state department } \\
\text { Collaboration with school districts } \\
\text { Collaboration with professional associations/agencies } \\
\text { Collaboration with state universities } \\
\text { Leadership }\end{array}$ & $1,2, \& 5$ \\
\hline & $\begin{array}{l}\text { Policy change } \\
\text { RtI/MTSS } \\
\text { Program evaluation }\end{array}$ & $1,2,5,9, \& 10$ \\
\hline
\end{tabular}

In Theme 2, collaboration was described as a community of interactions that occurred across the SSPCs' job responsibilities. All of the participants described their collaborative roles and efforts with colleagues in the SEAs, local school districts, community agencies, and higher education training programs to support a variety of professional activities (e.g., professional development, preparation of future school psychologists, special education law compliance). Such collaborative partnerships fulfill the SSPC position requirements by creating and maintaining a multi-tiered continuum of services to support academic, social, emotional, and behavioral progress for all students while advocating for implementation of policies and practices that promote conducive learning environments. Thus, there appeared to be a strong connection between the SSPCs' collaboration efforts based on the second NASP practice domain, Consultation and Collaboration, and the fifth domain, School-Wide Practices to Promote Learning. Also, by collaborating with professionals from other departments at the SEAs as well as local school districts, SSPCs utilized data to guide their service and decision-making process. This can be seen as an example of applying the first NASP domain, Data-Based Decision Making and Accountability, in the process of collaboration. In all, the SSPCs described enjoying collaboration and the need for greater collaboration within the state, community, and national levels so the guidelines of the NASP practice model could be better implemented.

In Theme 3, the participating SSPCs reportedly dedicated efforts to continuous systemic improvement for more effective service delivery to meet expectations and reach identified goals in various state improvement plans. Such statewide efforts addressed the fifth NASP domain, School-Wide Practices to Promote Learning, as its collaboration and incorporation of evidence-based strategies in the design, implementation, and evaluation of effective policies and practices. For instance, statewide policy change would rely on ongoing collaboration between the SSPC, cross-domain professionals, and local stakeholders to maximize its effectiveness and sustainability. Such working relationships can be accounted for as evidence of applying the second NASP domain: Consultation and Collaboration. Also, the use of program evaluation strategies and accountability-driven practice for guiding systemic improvement is commensurate with the spirit of the first NASP domain, Data-Based Decision Making and Accountability, as well as the ninth domain, Research and Program Evaluation. Finally, the efforts to align school psychologists' job responsibilities and evaluation using the NASP practice model as the framework can be considered as an example of connecting professional standards to strengthening school psychologist practitioners' professional practice and identity as outlined in the tenth NASP domain: Legal, Ethical, and Professional Practice.

\section{DISCUSSION}

There was an emerging phenomenon related to the role of SSPCs, who utilize their professional knowledge and skills to support translation of federal law requirements (e.g., ESSA) and the NASP practice model into state and local policies and practices. Because of the potential influence of the SSPC position, five SSPCs were recruited for interviews. The responses were closely examined to gain a better understanding of their job responsibilities and perceptions of the SSPC role and leadership responsibilities in promoting school psychological services based on the NASP practice model. Although the current study did not directly examine evidence of student outcomes resulted from adopting the NASP practice model, it has been suggested by the NASP that the implementation of its practice 
model can help schools improve student learning outcomes and school climate (Cowan, 2010). It is also recommended that the promotion and implementation of these professional standards can help strengthen school psychologists' professional identity and work competencies (NASP, 2010). Therefore, as an initial step in this research line, it is meaningful to begin with studying SSPCs' job responsibilities and their alignments with the NASP practice domains.

The findings of our research are promising for showing how the SSPCs perceive their roles as related to the NASP practice model as well as how they are utilizing the NASP practice model. One encouraging finding is that the domains of Data-Based Decision Making and Accountability and Consultation and Collaboration were present in all of the identified themes (i.e., service provision, collaborative roles and efforts, system improvement across the state). We find this result encouraging because NASP's conceptualization of these two domains permeates all aspects of school psychological services (NASP, 2010). As such, our findings provide evidence that the roles and functions of SSPCs are congruent with the NASP's professional expectations and recommendations.

The fifth NASP domain, School-Wide Practices to Promote Learning, was observed across all the identified themes addressing the SSPCs' perceptions of their current roles. Although this domain is not conceptualized to permeate all of school psychological service delivery for practitioners, given their leadership role and functions as statewide consultants, all of the interviewed SSPCs perceived their role to be focused on system-level practices when involving a variety of supportive activities (e.g., organizing professional development events, monitoring budgets, coordinating resources). Further, NASP domains Research and Program Evaluation and Legal, Ethical, and Professional Practice were observed in Theme 3, system improvement across the state. These domains are conceptualized by NASP to be foundational to school psychological services delivery. This finding provides additional evidence that the SSPCs perceived themselves to be engaged in foundational school psychological practices.

In brief, the perceived SSPCs' roles and functions were closely aligned with the inter-related NASP practice domains, including practices that permeate all aspects of school psychological service delivery, systems-level services, as well as foundational services applying program evaluation and promoting legally and ethically sound practices. The services provided by the SSPCs can be integrated to best meet the needs of students, families, and the school community. More detailed discussion of each theme follows.

\section{Service Provision by SSPCs}

The NASP website states, "Always remember that the goal in enhancing your practice is to better serve students, families, and schools" (NASP, n.d.). Thus, it is not surprising that the SSPCs perceived much of their role to be related to service provision, which is a critical component of the NASP practice model. Indeed, five of the 10 NASP domains are categorized as being either direct or indirect services. Among these five services-related domains, two address student-level success (i.e., Intervention and Instructional Support to Develop Academic Skills and Interventions and Mental Health Services to Develop Social and Life Skills), and the other three address systems-level services (i.e., School-Wide Practices to Promote Learning, Preventive and Responsive Services, and Family-School Collaboration Services). Much of the NASP practice model for direct and indirect services discusses the importance of EBPs. Clearly, it is paramount that school psychologists implement EBPs when working with students, families, and schools in order to increase the likelihood of observing desired outcomes.

As previously stated, elements related to the domains of Data-Based Decision Making and Accountability as well as Consultation and Collaboration were noted within the service provision theme. The promotion of coordinated use of data can help school and district leadership teams with using evidence-based learning supports and more effective problem solving to maintain accountability. Among the two levels of service outlined in the NASP practice model, it is unlikely to expect the SSPCs to be involved with direct service provision to students (i.e., the two domains under student-level success); rather, it is more likely for them to provide indirect services to promote EBPs at the state level. One of our major findings is that the SSPCs perceived being engaged in School-Wide Practices to Promote Learning; all of the participating SSPCs served districts and schools by assisting them with applying the law, organizing professional development, and efficiently allocating their mental health and educational resources. Nevertheless, it was unclear from our data whether the SSPCs perceived themselves to be engaged in services to families or working with schools to assist them in facilitating family-school partnerships, which is equally emphasized in the ESSA (2015) and the NASP practice model. 


\section{SSPCs' Collaborative Roles and Efforts}

The SSPCs perceiving their role as being highly collaborative is unsurprising as well. Our results suggested that the SSPCs actively engaged in multi-level collaboration with their colleagues in the SEAs, with people in local districts, university training programs, and a variety of professional associations/agencies across the states for directly and indirectly serving their students. Additionally, the ESSA (2015) authorizes funds for the development and maintenance of school-community partnerships, which require efforts to help eliminate barriers to coordination of services and integration of funding streams.

For example, the SSPCs mentioned their ongoing efforts to engage in statewide collaboration with different professional agencies to create more comprehensive health systems beyond schools. Such work of organizing useful community-based mental health resources accessible for families and schools in a larger societal system can benefit a child as well as the functions of his or her school and family. In response to a call for creating resource-oriented systems with the focus of weaving together existing school and community resources (Adelman \& Taylor, 2000), an SSPC's collaborative role can help ensure that system-wide resources are designed and utilized in an increasingly cohesive way. As described in the theme of collaboration, an SSPC can be in the driver's seat for guiding an entire state's mental health service provision by developing comprehensive approaches for preventing and ameliorating problems, creating readiness for systemic change, and providing professional development across sites in the state.

In all, an SSPC's statewide collaboration encouraged by the NASP practice model seems to help address the ESSA's (2015) requirement of providing equity of learning resources across school districts and effective services to all students.

\section{SSPCs' Involvement in System Improvement}

The NASP practice model can be seen as a system of effective delivery of EBPs in schools with support from the competencies and skills of school psychologists (Eklund et al., 2016). Given the SSPCs' potential involvement in their states' systemic reform, the three core ideas identified in Theme 3, policy change, RtI/MTSS, and program evaluation, point out the field's ongoing efforts to improve the structure of school systems to better meet our students' diverse learning needs. The implementation of RtI/MTSS, for example, requires effective collaboration within a school system (e.g., general education, special education, administrators, supportive staff) and incorporation of EBPs in the design, implementation, and evaluation of policies and practices (Little, Marrs, \& Bogue, 2017; Marrs \& Little, 2014). Essential to RtI/MTSS is the use of evidence-based instruction and interventions within a continuum of tiered supports. Universal screening and progress monitoring are assessment tools that can help determine what levels of supports are needed, how to integrate and allocate implementation resources, and how to utilize evaluation data for systemic improvement over time (Fuchs, Fuchs, \& Compton, 2012). Since the SSPC's leadership and school psychologists' involvement are expected in systemic reforms (e.g., an adoption of RtI/MTSS at the state level of practice), they should collaborate with building leaders and teachers to implement universal, targeted, and intensive academic and behavioral support programs using EBPs in local school districts (NASP, 2006).

Our interview findings also suggest that school psychologists' involvement in the RtI/MTSS movement has promoted an emerging work of refining their job responsibilities as well as job evaluation procedures. However, the potential impact on current school psychology practitioners' professional identity and efficacy of such an initiative mentioned in the NASP domain Legal, Ethical, and Professional Practice remains understudied (Marrs \& Little, 2014). For instance, while moving toward applying instruction-based models to identify and serve students with SLD, the traditional role and identity of the school psychologist as a psychometrician or tester may be challenged. It is important to know whether this is true for school psychologist practitioners as they begin to experience the role change and the modification of their professional identify as being more involved in the implementation of RtI/MTSS.

Collectively, the reported activities by the SSPCs streamlined in Theme 3 regarding their involvement in system improvement for more effective practice across their states (e.g., reframing SLD policies, reconceptualization of school psychologists' job responsibilities, and evaluation using the NASP practice model) provide solid evidence that the SSPCs perceived that they are building education systems' capacity for meeting diverse learning needs from all students as recommended in the ESSA (2015). 


\section{Limitations and Directions for Future Research}

Given the exploratory nature of this study, limitations in terms of methodology were recognized. The SSPC contacts provided by the NASP Research Committee were based on the results of queries to each state's professional association of school psychologists rather than directly reaching out to the SEAs. Therefore, the directory with the 29 state consultants might not be an exhaustive list, which would be a likely limitation of the data. In addition, the SSPCs were recruited using purposeful sampling to ensure that the participants accurately represented the studied phenomenon (Creswell, 2013). One potential limitation of using this method is its homogeneous group (i.e., SSPCs working full time for the SEAs), which may limit diverse perspectives. Further, since the current sampling excluded those SSPCs who only acted as advisors for SEAs but primarily worked for state universities or local school districts, the generalizability of the findings based on the full-time SSPCs to those part-time positions may be limited because of the representation of the sample. However, this specific population was selected to allow the current findings to be useful for creation of new full-time SSPC positions and/or continuous improvement of the existing SSPC positions' roles and functions. Thus, the case study design with purposeful sampling was deemed to be appropriate for the purpose of the current study. Finally, challenges could also arise with the amount of information the SSPCs were willing to share due to their authority/administrative role in the SEAs as well as the limited time for warming up during the brief interview process (i.e., 30 to 45 minutes).

Given the richness of the authentic information shared, several directions for future research can be considered. First, the adoption of RtI/MTSS models for SLD evaluation appeared to be one of SSPCs' several major job responsibilities. Future research may consider further exploring SSPCs' leadership role in the SLD policy reframing and program evaluation efforts across the nation. Since such involvement in system-level change requires substantial knowledge and skills, another follow-up study may consider exploring professional development needs perceived in the SSPC role as a state-level leader.

Second, although the SSPCs were reportedly involved in indirect school-wide practices to promote student learning (e.g., RtI/MTSS), the other two NASP domains related to systems-level services, Preventive and Responsive Services and Family-School Collaboration Services, seemed under-addressed in the current findings. Given the collaborative nature of the SSPC position, future research can further study SSPCs' leadership role in strengthening EBPs to support family influences on students' mental health and explore strategies to strengthen effective family-school collaboration.

Third, as also mentioned in the findings, partnerships between SSPCs and higher education seem promising. However, there is a need for clearer contractual descriptions regarding both parties' responsibilities and operations to create a long-term and mutually benefiting collaboration relationship. Empirical studies are warranted to further examine potential outcomes of such efforts for generalization of successful partnerships such as in scholarly productivity and university trainees' field supervision and professional development.

Finally, a potential application of standardized job evaluation rubrics created and offered by the SEAs for practicing school psychologists was noted. Due to differences in the serving regions (e.g., urban, suburban, rural) as well as variant types of school psychologist positions (e.g., full-time employee, part-time contractor), it is reasonable to investigate the ways (with or without modification of the evaluation rubrics) and related effects (e.g., boosting job performance, increasing work motivation) regarding such use. Balancing outcome evaluation (e.g., job performances based on certain practice standards) and addressing practical issues raised by stakeholders are equally important for effective evaluation (Chen \& Garbe, 2011). For instance, factors related to job satisfaction regarding SLD identification among practicing school psychologists have been emerging in the literature (e.g., Cottrell \& Barrett, 2016; Unruh \& McKellar, 2013). Leaders and/or administrators in LEAs may consider assessing the variable of job satisfaction as part of their job evaluations for refining their current guidelines for practice.

\section{AUTHOR BIOGRAPHIES}

Chung-Hau Fan, Ph.D., NCSP, is an associate professor in the Department of School Psychology and Educational Leadership at Idaho State University. His current research focuses on improving response-to-intervention (RTI) methodologies, including reduction of measurement error for progress monitoring and systemic troubleshooting for effective RTI implementation. Other areas of interest include special education leadership, clinical supervision in 
school-based training, nondiscriminatory cognitive assessment with cross-cultural students, and autism spectrum disorders.

Jenn Gallup, Ph.D. is an assistant professor of the Special Education Program at Idaho State University with a focus on inclusion through effective integration of universal design for learning (UDL) particularly in STEM. She publishes and disseminates research in the areas of autism and effective integration technologies such as video games, simulations, and virtual environments, that support and develop interpersonal relationships and soft-skills required for STEM careers.

I-Chen Wu, M.A. is a graduate student in the Department of Educational and Counselling Psychology, and Special Education at the University of British Columbia. Her research interests include learning experiences and strengthbased approaches, self-determination, self-knowledge, self-advocacy, program evaluation, creativity, and education for students with special needs (highly able learners, twice-exceptional students, and students with learning and attention challenges).

Jeremy W. Ford, Ph.D., NCSP, is an assistant professor in the Department of Early and Special Education at Boise State University. His research interests include curriculum-based measurement (CBM), explicit instruction, postsecondary transition and education for students with disabilities, multi-tiered systems of support (MTSS), and screening and progress decision-making.

\section{REFERENCES}

Adelman, H. S., \& Taylor, L. (2000). Shaping the future of mental health in schools. Psychology in the Schools, 37, 49-60.

Bloomberg, L. D., \& Volpe, M. (2012). Completing your qualitative dissertation: A road map from beginning to end (2nd ed.). Thousand Oaks, CA: Sage.

Chen, H. T., \& Garbe, P. (2011). Assessing program outcomes from the bottom-up approach: An innovative perspective to outcome evaluation [Special issue]. New Directions for Evaluation, 130, 93-106. doi:10.1002/ev.368

Cottrell, J. M., \& Barrett, C. A. (2016). Job satisfaction among practicing school psychologists: The impact of SLD identification. Contemporary School Psychology, 20(1), 21-30. doi:10.1007/s40688-015-0076-4

Cowan, K. C. (2010). The NASP practice model. A framework for promoting and implementing a comprehensive role. Communiqué, 39(4), 14.

Creswell, J. (2013). Qualitative inquiry and research design: Choosing among five approaches (3rd ed.). Thousand Oaks, CA: SAGE.

Eklund, K., Rossen, E., Charvat, J., Meyer, L., \& Tanner, N. (2016). The National Association of School Psychologists' selfassessment tool for school psychologists: Factor structure and relationship to the National Association of School Psychologists' practice model. Journal of Applied School Psychology, 32(2), 122-142. doi: $10.1080 / 15377903.2016 .1151848$

ESSA. (2015). Every Student Succeeds Act of 2015. Pub. L. No. 114-95 § 114 Stat. 1177 (2015-2016).

Florida Department of Education. (n.d.). The Florida Department of Education (FLDOE) consultant. Retrieved from http://www.fasp.org/Liaison_Positions/DOE_Consultant.html

Fuchs, D., Fuchs, L. S., \& Compton, D. L. (2012). Smart RTI: A next-generation approach to multilevel prevention. Exceptional Children, 78(3), 263-279.

Hays, D. G., \& Singh, A. A. (2011). Qualitative inquiry in clinical and educational settings. Thousand Oaks, CA: SAGE.

Little, S., Marrs, H., \& Bogue, H. (2017). Elementary school psychologists and response to intervention (RTI). Contemporary School Psychology, 21, 103-114. doi: 10.1007/s40688-016-0104-z

Marrs, H., \& Little, S. (2014). Perceptions of school psychologists regarding barriers to response to intervention (RTI) implementation. Contemporary School Psychology, 18, 24-34. doi: 10.1007/s40688-013-0001-7

Moustakas, C. (1994). Phenomenological research methods. Thousand Oaks, CA: Sage.

National Association of School Psychologists. (2010). Model for comprehensive and integrated school psychological services. Retrieved from https://www.nasponline.org/standards-and-certification/nasp-practice-model

National Association of School Psychologists (NASP) (n.d.). Benefits of Adopting the NASP Practice Model. Retrieved from https://www.nasponline.org/standards-and-certification/nasp-practice-model/nasp-practice-model-implementationguide/section-v-advocacy-steps-for-promoting-the-nasp-practice-model/benefits-of-adopting-the-nasp-practie-model

National Association of School Psychologists. (2006). The role of the school psychologist in the RTI process. Retrieved from https://www.nasponline.org/Documents/Research\%20and\%20Policy/Advocacy\%20Resources/Psychological\%20Servi ces/MASP_RTI.pdf

Reschly, D. J. (2008). School psychology paradigm shift and beyond. In A. Thomas \& J. Grimes (Eds.), Best Practices In School Psychology V (pp. 3-15). Bethesda, MD: National Association of School Psychologists.

Copyright by author(s); $\underline{\text { CC-BY }}$ 
Simon, M. K., \& Goes, S. (2012). What is phenomenological research? Dissertation and Scholarly Research: Recipes for Success. Retrieved from http://dissertationrecipes.com/wp-content/uploads/2011/04/Phenomenological-Research.pdf.

Unruh, S., \& McKellar, N. A. (2013). Evolution, not revolution: School psychologists' changing practices in determining SLD. Psychology in the Schools, 50(4), 353-365.

Wisconsin Department of Public Instruction. (n.d.). School psychology: What is a school psychologist? Retrieved from https://dpi.wi.gov/sspw/pupil-services/school-psych

Yin, R. K. (2014). Case study research design and methods (5th ed.). Thousand Oaks, CA: Sage.

Ysseldyke, J. E., Reynolds, M. C., \& Weinberg, R. A. (1984). School psychology: A blueprint for training and practice. Minneapolis, MN: National School Psychology In-service Training Network, University of Minnesota. 
NOTES 